\title{
Two new species of Simulium Latreille (Diptera: Simuliidae) from northwestern Thailand
}

\author{
Hiroyuki TAKaоKa ${ }^{1)}$ and Wej CHоосноте ${ }^{2)}$ \\ 1) Department of Infectious Disease Control, Faculty of Medicine, Oita University, \\ Hasama, Oita, 879-5593 Japan \\ 2) Department of Parasitology, Faculty of Medicine, Chiang Mai University, \\ Chiang Mai 50200, Thailand
}

(Received: 16 March 2005; Accepted: 22 April 2005)

\begin{abstract}
Two new species of Simulium Latreille s.l. are described based on specimens collected from Phop Phra, Tak Province, in northwestern Thailand. Simulium prayongi sp. nov. is assigned to the batoense species-group of the subgenus Gomphostilbia, and is characterized by the pupal gill composed of two inflated elements and eight slender filaments. Simulium takense sp. nov. is assigned to the multistriatum species-group of the subgenus Simulium s. str., and is easily distinguished in the pupa from other known species of this species-group by a combination of the shoe-shaped cocoon, the pupal gill with eight gill filaments widely divergent, and the presence of distinct spine-combs and terminal hooks on the 9th abdominal segment.
\end{abstract}

Key words: black fly, Simulium, Simuliidae, Thailand, new species

During recent surveys on aquatic stages of black flies in Phop Phra, Tak Province, northwestern Thailand, we collected two new species of the genus Simulium Latreille s.l., of which one belongs to the subgenus Gomphostilbia Enderlein, and the other to the subgenus Simulium Latreille s. str. These two new species are described based on the reared adults and pupal exuviae.

The terms for morphological features used here follow those of Takaoka (2003). Holotype and paratype specimens of the new species are deposited at the Department of Infectious Disease Control, Faculty of Medicine, Oita University, Oita, Japan.

\section{Simulium (Gomphostilbia) prayongi sp. nov.}

DESCRIPTION. Male. Body length 2.0-2.7 $\mathrm{mm}$. Head. Much wider than thorax. Upper eye consisting of 14 or 15 vertical columns and 16 horizontal rows of large facets. Face brown- ish-black, thickly white pruinose. Clypeus brownish-black, white pruinose, moderately covered with golden yellow short and long hairs, intermixed with several dark brown long hairs on lower portion. Antenna composed of 2 +9 segments, yellow on scape, pedicel, and base of 1st flagellar segment, and dark yellow or light brown to brownish-black on rest (gradually darkened toward apex); 1st flagellar segment somewhat elongate, 1.6 times as long as 2nd flagellar segment. Maxillary palp composed of 5 segments, greyish brown, proportional lengths of $3 \mathrm{rd}, 4 \mathrm{th}$, and 5 th segments $1.00: 1.35: 3.24$; sensory vesicle (Fig. 1A) small, ellipsoidal, 0.26 times as long as 3rd segment. Thorax. Scutum black though somewhat brownish-black laterally, faintly white pruinose along lateral margins and on prescutellar area, shiny at certain angle of light, and densely covered with golden yellow short hairs. Scutellum brownish-black, densely covered with golden yellow short hairs as well as several dark brown long upright hairs. Postnotum brownish-black, white pruinose, shiny at certain angle of light, and bare. Pleural membrane 
bare. Katepisternum longer than deep, moderately covered with yellow short hairs as well as dark ones. Legs. Foreleg: coxa whitish-yellow; trochanter, femur, and tibia medium brown except apical cap of tibia brownish-black; tarsus brownish-black; basitarsus somewhat dilated, 6.9 times as long as its greatest width. Midleg: coxa dark brown; trochanter and femur light to medium brown except apical cap of femur brownish-black; tibia brownish-black except a little more than basal $1 / 4$ yellow; tarsus brownish-black except basal $1 / 3$ of basitarsus light to medium brown. Hind leg: coxa medium brown; trochanter yellow; femur medium brown except apical cap brownish black; tibia yellow on basal $2 / 5$ or a little more, and brownish-black on rest; tarsus dark brown to brownish-black except basal $1 / 2$ or a little more of basitarsus, and basal 1/2 of 2 nd segment yellow; basitarsus (Fig. 1B) somewhat widened, spindle-shaped, 4.75 times as long as wide, and 0.73 times as wide as greatest widths of tibia and femur (latter two subequal in width to each other); calcipala well developed, 1.2 times as long as wide; pedisulcus well developed. All femora, tibiae, and parts of tarsi densely covered with scale-like hairs as well as usual simple hairs at least on outer and posterior surfaces. Wing. Length $1.8 \mathrm{~mm}$. Costa with spinules and hairs. Subcosta bare. Hair tuft on stem vein golden yellow. Basal portion of radial vein fully haired. $R_{1}$ with spinules and hairs. $\mathrm{R}_{2}$ with hairs only. Basal cell, and basal median cell absent. Abdomen. Basal scale brownish-black, with fringe of dark long hairs. Dorsal surface of abdomen medium brown to brownish-black except basal 1/2 of segment 2 white, with dark brown short hairs; segments 2, 5-7 each with a pair of shiny large dorsolateral patches. Genitalia. Coxite (Fig. 1C) large,

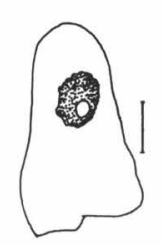

A

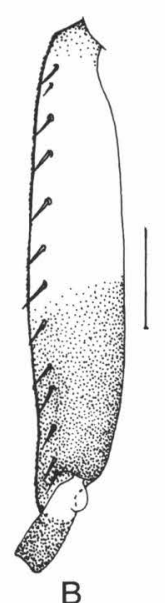

B
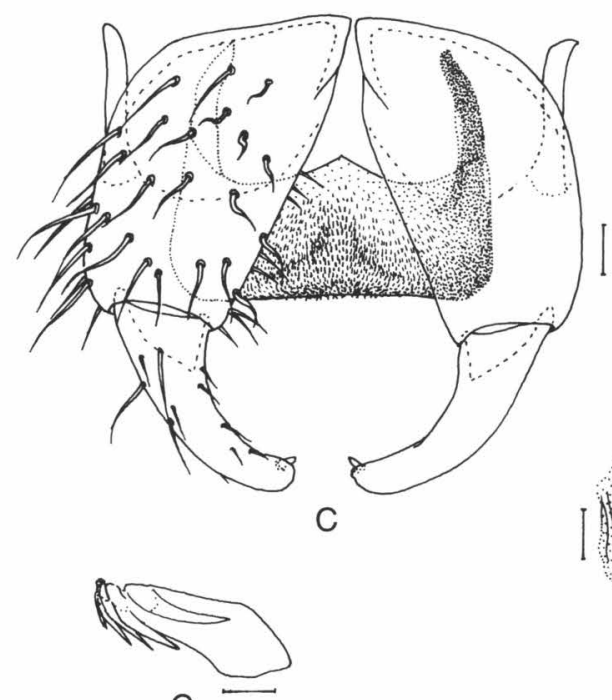

G

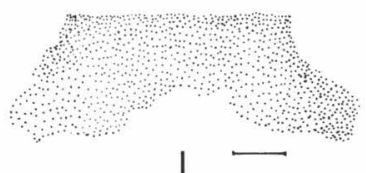

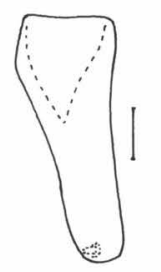

D

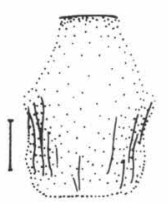

$\mathrm{H}$

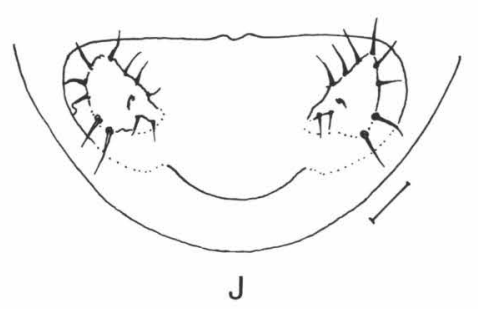

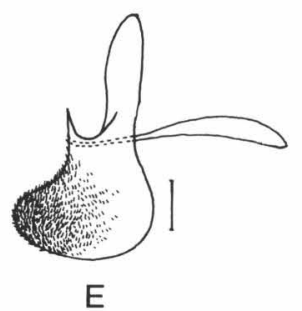

$\mathrm{E}$

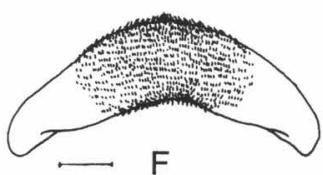

F

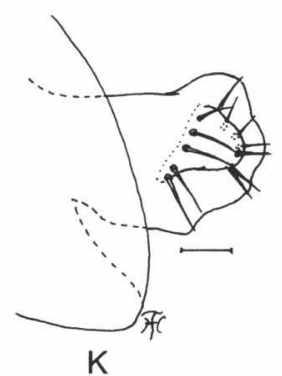

Fig. 1. Adult male of Simulium (Gomphostilbia) prayongi sp. nov. A, 3rd segment of maxillary palp showing sensory vesicle; B, basitarsus and 2nd tarsal segment of hind leg; C, coxites, styles and ventral plate in situ (ventral view); D, style (ventrolateral view); E, ventral plate and median sclerite (lateral view); F, ventral plate (end view); G, paramere (end view); H, median sclerite (end view); I, dorsal plate (ventral view); J and $\mathrm{K}, 10$ th abdominal segments and cerci (J, end view; $\mathrm{K}$, lateral view). Scale bars. $0.1 \mathrm{~mm}$ for B; $0.02 \mathrm{~mm}$ for A and C-K. 
subquadrate, 1.8 times as long as wide when viewed ventrally. Style (Fig. 1C, D) much shorter than coxite, gently curved inward, gradually tapered toward apex, with single apical spine. Ventral plate in ventral view (Fig. 1C) transverse, much shorter than wide, with lateral margins slightly narrowed anteriorly, densely covered with microsetae on ventral surface; basal arms directed forward and then somewhat inward; ventral plate in lateral view (Fig. 1E) moderately produced ventrally near posterior margin; ventral plate in end view (Fig. $1 \mathrm{~F}$ ) rounded ventrally, densely covered with microsetae centrally on posterior surface. Paramere (Fig. 1G) narrow, with several hooks decreasing in length from dorsal to ventral. Median sclerite (Fig. 1H) broad, widened basally, then nearly parallel-sided. Aedeagal membrane uniformly covered with microsetae. Dorsal plate (Fig. 1I) wide, thin, weakly sclerotized. Ventral surface of 10th abdominal segment (Fig. 1J, K) without any distinct hair near posterior margin on each side. Cercus (Fig. 1J, $\mathrm{K})$ rounded, encircled with 11 or 12 hairs.

Pupa. Body length ca. $2.5 \mathrm{~mm}$. Head. Integument light yellowish-brown, moderately or densely covered with round tubercles; anten- nal sheath bare; head with 1 facial and 3 frontal pairs of bifid or trifid long trichomes. Thorax. Integument light yellowish-brown, moderately covered with round tubercles on anterior $2 / 3$, and almost bare on posterior $1 / 3$; thorax (Fig. 2 A) with 3 long trichomes ( 1 simple and 2 bifid or trifid) mediodorsally, 2 long trichomes (1 simple and 1 bifid, or 2 bifid) anterolaterally, 1 medium-long bifid or trifid trichome posterolaterally, and 3 medium-long simple trichomes ventrolaterally, on each side. Gill (Fig. 2A) composed of $\mathrm{V}$-shaped inflated structure in lateral view, with 8 slender thread-like filaments; ventral inflated element $(0.7-0.8 \mathrm{~mm}$ long) directed forward, with 2 or 3 round projections at apex (all or some are nodule-like or thumb-like, as shown in Fig. 2B), and dorsal inflated element (0.5-0.6 mm long) directed forward and upward, at about 60 degree to ventral inflated element, with 2 or 3 round projections at apex (at least 1 nodule-like or thumblike); surface of both inflated elements and their basal stalk (Fig. 2C) light brown, with numerous small round or cone-shaped processes, and densely covered with minute tubercles; of 8 slender thread-like filaments, 1 (ca. 0.4 $\mathrm{mm}$ long) arising from apex of dorsal inflated

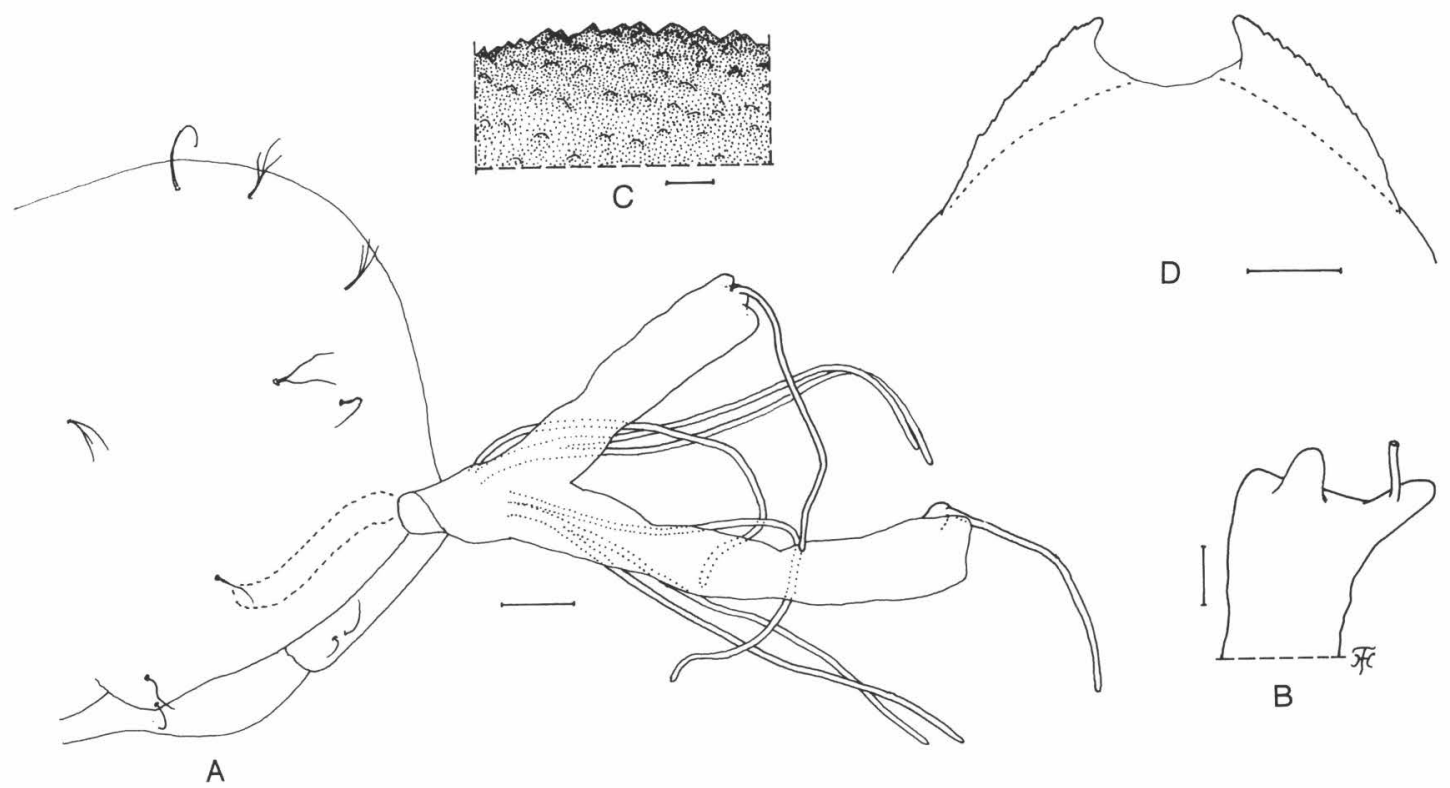

Fig. 2. Pupa of Simulium (Gomphostilbia) prayongi sp. nov. A, thoracic integument with gill (right side, outer view); B, apical portion of ventral inflated element showing two thumb-like projections (dorsal view); C, part of surface of inflated element showing round or cone-shaped processes and minute tubercles (lateral view); D, terminal hooks (end view). Scale bars. $0.1 \mathrm{~mm}$ for A; $0.05 \mathrm{~mm}$ for B; 0.02 $\mathrm{mm}$ for $\mathrm{D} ; 0.01 \mathrm{~mm}$ for C. 
element, 1 (ca. $0.3 \mathrm{~mm}$ long) arising from lateral surface of inner thumb-like projection of apex of ventral inflated element, and remaining 6 (ca. $0.6 \mathrm{~mm}$ long) arising from inner surface of inflated basal stalk, arranged in 2 separate groups of 1 individual and 2 paired filaments with stalk of moderate length; all these slender filaments light brown, subequal in thickness, without distinct annular ridges and furrows, and densely covered with minute tubercles. Abdomen. Dorsally, all segments nearly transparent or very weakly sclerotized except segment 9 moderately sclerotized and yellowishbrown almost entirely; segment 1 with 1 medium-long simple dark hair on each side; segment 2 with 1 medium-long simple dark hair and 5 short pale spines on each side; segments 3 and 4 each with 4 dark stout hooks and 1 short pale spine on each side; segment 5 bare; segments 6-9 each with spine-combs and comb-like groups of minute spines lying transversely along anterior margin on each side; terminal hooks (Fig. 2D) distinct, platelike, with serrated outer margin. Ventrally, segments 3-8 nearly transparent and segment 9 weakly sclerotized and yellowish; segment 4 with 1 simple dark hook (subequal in size to those on segments 5-7) and a few short simple setae on each side; segment 5 with 2 bifid dark hooks and a few short simple setae on each side; segments 6 and 7 each with 1 bifid inner and 1 simple outer dark hooks, and a few short simple setae on each side. Segment 9 with 3 grapnel-shaped hooklets on each lateral side. Cocoon. Simple, wall-pocket-shaped, tightly woven, with anterodorsal margin somewhat thickly woven, and extending ventrolaterally; floor woven on posterior $1 / 2$; individual threads indistinct; $3.0 \mathrm{~mm}$ long by $1.6 \mathrm{~mm}$ wide.

Female and Mature larva. Unknown.

TYPE SPECIMENS. Holotype male with its associated pupal exuvia and cocoon, collected at Nang Khruan Waterfall, Phop Phra District, Tak Province, Thailand, 14. I. 2005, by W. Choochote. Paratype: 1 male with its associated pupal exuvia and cocoon, same data and date as those of the holotype.

ECOLOGICAL NOTES. Only two pupae of $S$. $(G$.) prayongi sp. nov. were collected from dead leaves in the water of a small stream (width ca. $1 \mathrm{~m}$, depth ca. 5 $\mathrm{cm}$, water-current moderate, shaded, water temperature $24^{\circ} \mathrm{C}$, altitude $420 \mathrm{~m}$ ).

Associated species was $S$. (S.) takense sp. nov.

ETYMOLOGY. The species name prayongi is in honor of Professor Emeritus Prayong Radomyos, Consultant, Faculty of Tropical Medicine, Mahidol University, Bangkok, Thailand, from whom WC learned much during his master course.

REMARKS. According to the keys (Takaoka, 2003), S. (G.) prayongi sp. nov. is assigned to the batoense species-group of the subgenus Gomphostilbia by having the antenna with nine flagellar segments, the pleural membrane bare, the hind basitarsus not so enlarged in the male, pupal gill with eight slender filaments. This new species is remarkable within this speciesgroup by having the pupal gill of inflated structure (Fig. 2A). There have been only three species in the batoense species-group with such inflated pupal gills, namely, $S$. (G.) gombakense Takaoka and Davies from Peninsular Malaysia (Takaoka and Davies, 1995; Takaoka, 2000), S. (G.) padangense Takaoka and Sigit from Sumatra (Takaoka and Sigit, 1997), and S. (G.) tumidum Takaoka from Sulawesi (Takaoka, 2003). Among these species, S. (G.) tumidum seems to be more closely related to $S$. $(G$.) prayong $i$ sp. nov. than the other two species, because it has a similar form of the pupal gill, i.e., two inflated elements and eight slender thread-like filaments, like this new species. However, S. (G.) prayongi sp. nov. differs from $S$. (G.) tumidum by the following characters (those of $S$. (G.) tumidum in parentheses): in the pupa, inflated elements of the gill appear V-shaped (Fig. $2 \mathrm{~A}$ ) in the lateral view ( $\mathrm{Y}$-shaped in the dorsal view), the presence of numerous round or cone-shaped processes on the inflated elements (Fig. 2C) (absence of such processes), six slender filaments arising in two separate groups from the inner sur- 
face of the inflated basal stalk (Fig. 2A) (all arising close together from the dorsal surface of the gill base), most trichomes on the head and thorax bifid or trifid (simple); in the male, large facets in the upper eye in 14 or 15 vertical columns and in 16 horizontal rows (in 11 vertical columns and in 12 horizontal rows), hind basitarsus white on the basal $1 / 2$ or a little more (Fig. 1B) (white on the basal 2/3).

\section{Simulium (Simulium) takense sp. nov.}

DESCRIPTION. Female. Body length 2.5$3.0 \mathrm{~mm}$. Head. Narrower than thorax. Frons black, shiny (bluish iridescent when illuminated), with several dark stout hairs along lateral margins; frontal ratio $1.35-1.38: 1.00$ : 1.35-1.40; frons-head ratio $1.0: 4.2$. Frontoocular area (Fig. 3A) well developed, short, directed laterally. Clypeus black, white pruinose, shiny (bluish iridescent when illuminated), moderately covered with dark stout hairs except upper $1 / 2$ widely bare medially. Labrum 0.80-0.87 times as long as clypeus. Antenna composed of $2+9$ segments, whitishyellow on scape, and most of pedicel, deep yellow or ocherous on 1st to 3rd (or to 4th) flagellar segments, and medium brown on rest of flagella in front view; 2nd to 3rd (or to 4th) flagellar segments partially brownish in posterior view. Maxillary palp with 5 segments, light to dark brown, proportional lengths of $3 \mathrm{rd}$, 4th, and 5th segments $1.0: 1.0: 2.1$; 3rd segment (Fig. 3B) of normal size, with large oblong sensory vesicle $(0.40-0.44$ times as long as 3rd segment) having medium-sized opening apically. Maxillary lacinia with 10-13 inner and 13-15 outer teeth. Mandible with ca. 30 inner and 14 outer teeth. Cibarium (Fig. 3C) with blunt median projection on posterior margin, and without any minute processes near base of median projection. Thorax. Scutum black, shiny, densely covered with whitish-yellow recumbent short hairs interspersed with dark short hairs on anterior surface, and also with several dark long upright hairs on prescutellar area; when illuminated in front and viewed dorsally, scutum thickly white pruinose, with 5 longitudinal unpruinose vittae, of which 1 median vitta is of moderate width, 2 submedian and 2 sublateral vittae rather wide (though sublateral vittae some- what wider than submedian ones), all vittae united with broad transverse band on prescutellar area; when illuminated from behind, scutum having reversed color pattern. Scutellum medium to dark brown, covered with dark upright long hairs as well as whitish-yellow short hairs. Postnotum dark brown to brownish-black, shiny, grey pruinose, bare. Pleural membrane bare. Katepisternum longer than deep, bare. Legs. Foreleg: coxa and trochanter yellowish-white; femur yellow on basal $1 / 2$, light brown on apical $1 / 2$ on outer surface; femur yellow extensively on inner surface except apical cap light to medium brown; tibia white except apical $3 / 10$ brownish black; tarsus brownish-black, with moderate dorsal hair crest; basitarsus greatly dilated, 4.4 times as long as its greatest width. Midleg: coxa brownish-black; trochanter whitish yellow to light brown; femur yellow on basal $1 / 3$ (or on basal $2 / 5$ or a little more) with light brown portions basally on ventral surface, light to medium brown on rest; tibia white to yellowish-white except apical 1/6 medium brown; tarsus brownish-black except basal $1 / 2$ or a little more of basitarsus yellowish white. Hind leg: coxa dark brown to blackish brown; trochanter whitish yellow; femur dark brown to brownish black except basal $3 / 10$ yellow; tibia white to yellowish white on basal $2 / 3$ or a little less, brownish black on rest; tarsus blackish brown except a little more than basal $1 / 2$ of basitarsus, and a little less than basal $1 / 2$ of 2nd segment yellowish white; basitarsus (Fig. 3 D) nearly parallel-sided, 5.4 times as long as wide, and 0.75 and 0.66 times as wide as greatest widths of hind tibia and femur, respectively; calcipala (Fig. 1D) moderately developed, slightly shorter than its width, not reaching level of pedisulcus; pedisulcus (Fig. 1D) well developed at basal $1 / 3$ of 2nd tarsal segment. All tarsal claws simple. Wing. Length $2.3 \mathrm{~mm}$. Costa with dark spinules and hairs; subcosta haired except near apex bare; basal section of radial vein bare; $\mathrm{R}_{1}$ with dark spinules and hairs; $\mathrm{R}_{2}$ with hairs; hair tuft on stem vein dark brown. Abdomen. Basal scale light to medium brown, with fringe of pale hairs. Dorsal surface of abdomen dark brown to brownish-black except basal $2 / 3$ of 2 nd segment yellowishwhite, with short dark hairs; tergite 2 shiny, white iridescent when illuminated, and tergites 6-8 shiny. Ventral surface of 7 th segment with pair of small submedian sternal plates. Geni- 


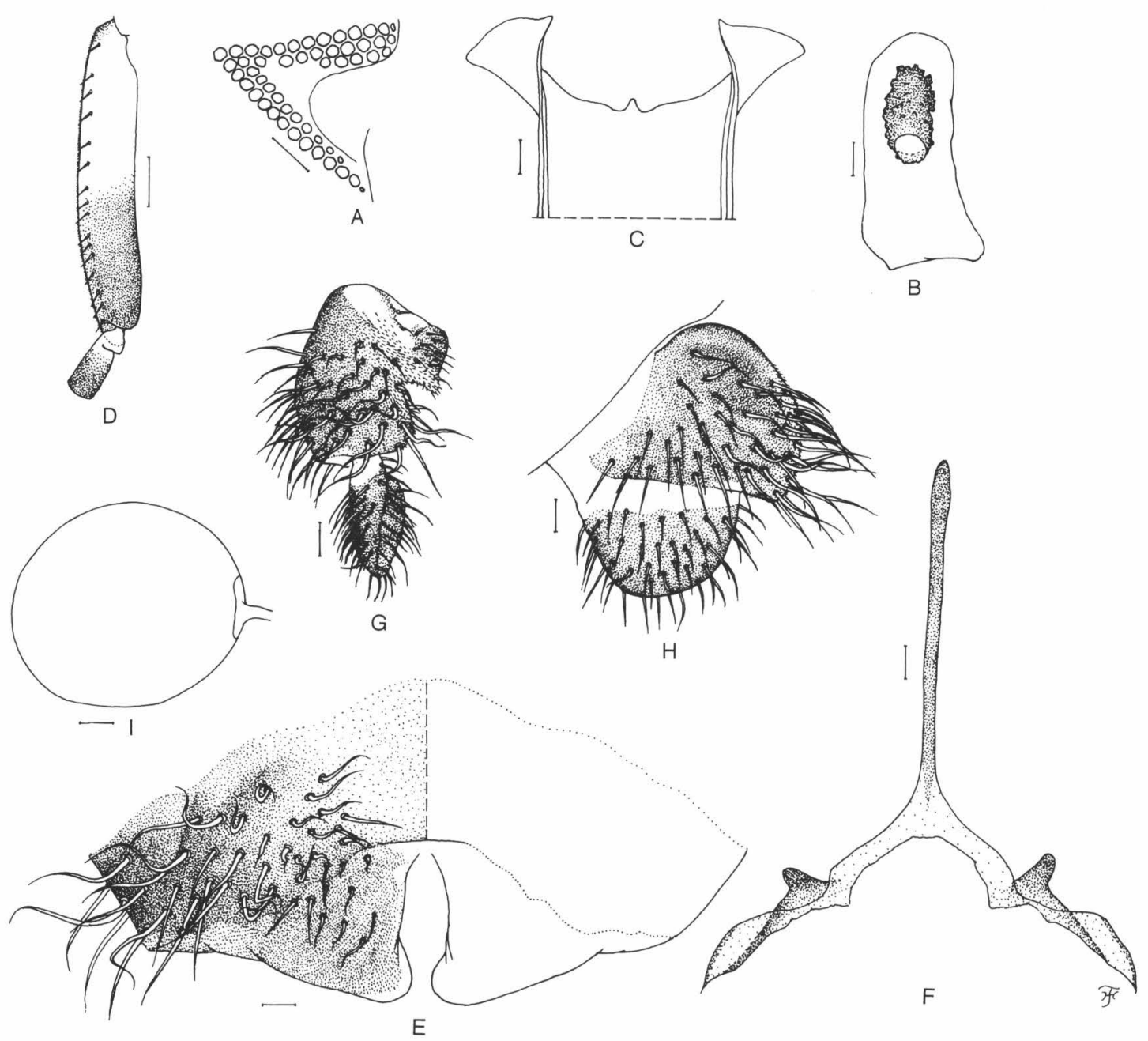

Fig. 3. Adult female of Simulium (Simulium) takense sp. nov. A, fronto-ocular area (right side); B, 3rd segment of maxillary palp with sensory vesicle (right side, front view); C, cibarium; D, basitarsus and second tarsal segment of hind leg showing calcipala and pedisulcus (left side, outer view); E, 8th sternite and ovipositor valves in situ (ventral view); F, genital fork (ventral view); G and $H$, paraprocts and cerci (right side; G, ventral view; H, outer view); I, spermatheca. Scale bars. $0.1 \mathrm{~mm}$ for D; $0.05 \mathrm{~mm}$ for A; $0.02 \mathrm{~mm}$ for $\mathrm{B}, \mathrm{C}$, and $\mathrm{E}-\mathrm{I}$.

talia. Sternite 8 (Fig. 3E) moderately sclerotized, ocherous medially, dark brown laterally, with ca. 40 dark medium-long to long stout hairs on each lateral surface. Ovipositor valves (Fig. 3E) triangular, rounded posteromedially, moderately separated from each other medially, membranous (except small portion near inner margin very weakly sclerotized), covered with numerous microsetae and $7-10$ pale (though a few dark) medium-long hairs (except narrow portion along inner margin, and also round tip of posteromedial corner bare). Genital fork (Fig. 3F) of inverted-Y form, with narrow well sclerotized stem; arms of moderate width, each with distinct projection directed anteriorly. Paraproct (Fig. 3G, H) strongly sclerotized on outer surface and moderately sclerotized on parts of anterior surface, moderately protruding ventrally beyond cercus, with numerous stout hairs on lateral and ventral surfaces, and with 12 or 13 short setae on anterior surface. Cercus (Fig. 3G, H) short, about half as long as wide, with numerous stout hairs, and rounded posteriorly when viewed laterally. Spermatheca (Fig. 3I) nearly ovoid, well sclerotized (except portion of junc- 


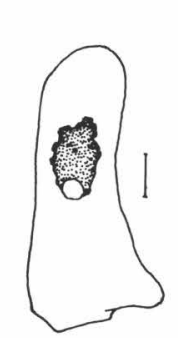

A
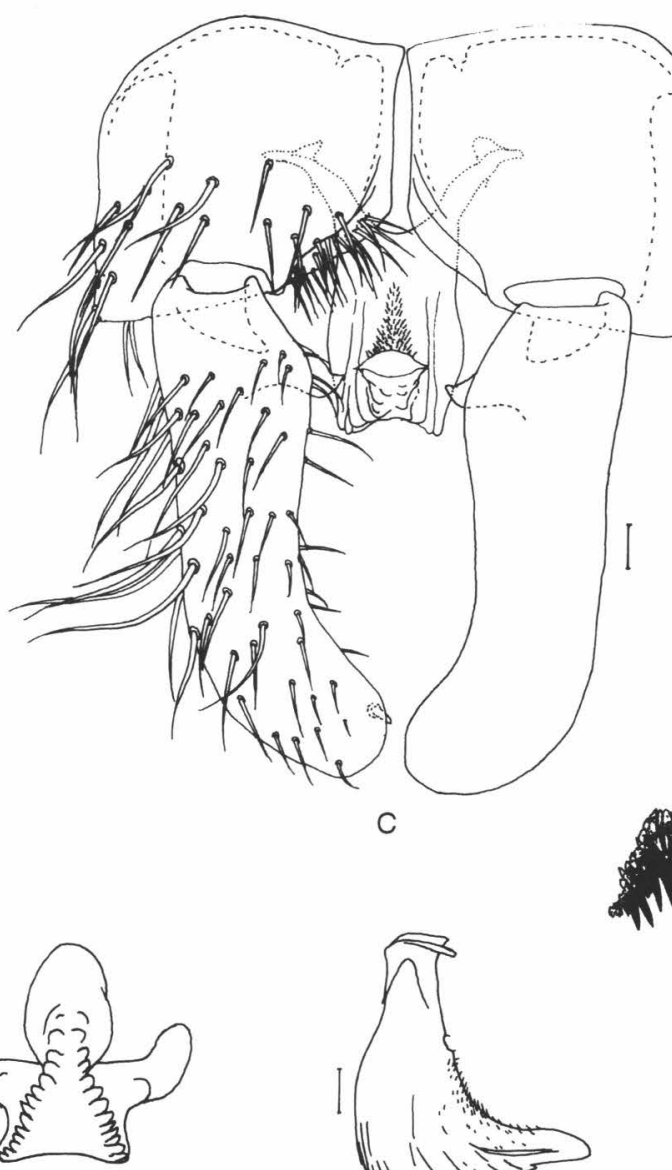
tion to duct unsclerotized), no reticulate surface patterns present, and with internal setae.

Male. Body length 3.0-3.4 mm. Head. Width subequal to that of thorax. Upper eye consisting of large facets in 20 or 21 horizontal rows and in 20 vertical columns. Clypeus black, thickly white pruinose (silvery iridescent when illuminated), sparsely covered with dark brown hairs along lateral and lower margins. Antenna composed of $2+9$ segments, yellowish-white on scape, and base of pedicel, dark ocherous to light brown on rest of pedicel, and 1st to 2nd (or to 3rd) flagellar segments, and medium brown on other flagellar segments (though gradually darkened toward apex); antenna in 1 male yellow on scape, pedicel, and 1st flagellar segment, light to medium brown on rest when viewed anteriorly, but almost light to medium brown except scape, base of pedicel, and basal $1 / 2$ of 1st flagellar segment yellow when viewed posteriorly; 1st flagellar segment elongated, 2.1 times as long as 2nd one. Maxillary palp brownish-black, composed of 5 segments with proportional lengths of $3 \mathrm{rd}$, 4 th, and 5th segments $1.0: 1.1: 2.6$; 3rd segment (Fig. 4A) of normal size; sensory vesicle of moderate size $(0.28-0.30$ times as long as 3 rd segment), ellipsoidal, and with medium-sized opening apically. Thorax. Scutum black, with white pruinose pattern, i.e., anterior pair of rectangular spots on shoulders extending posteriorly along lateral margins and connected to large transverse spot entirely covering prescutellar area; these pruinose areas silvery iridescent when illuminated at certain angles of light; scutum uniformly and densely covered with golden yellow recumbent short hairs interspersed with dark brown long upright hairs on prescutellar area. Scutellum dark brown, shiny, white pruinose, with several dark long upright hairs as well as golden yellow short hairs. Postnotum, pleural membrane and katepisternum as in female. Legs. Foreleg: coxa yellowish-white; trochanter and femur light brown though yellowish basally and gradually darkened toward apex on inner surface of femur; tibia medium brown to brownish black except median large portion of outer surface white, and with large white sheen when illuminated; tarsus brownish black to black, with moderate dorsal hair crest; basitarsus moderately dilated, 5.5 times as long as its greatest width. Midleg: coxa brownish-black; trochanter medium brown except base yellow- ish; femur medium brown (though light brown on inner surface); tibia yellowish-white except apical 1/4 medium brown; tarsus brownishblack except basal $1 / 2$ to $3 / 5$ of basitarsus white. Hind leg: coxa brownish-black; trochanter yellow; femur light to medium brown except base yellow and apical cap brownishblack; tibia medium brown to brownish-black except base whitish-yellow; tarsus dark brown to brownish-black except basal $2 / 5$ or a little less of basitarsus and a little less than basal $1 / 2$ of 2nd segment whitish-yellow; basitarsus (Fig. 4B) much enlarged, wedge-shaped, about 3.7 times as long as its greatest width, and 0.86 and 0.93 times as wide as greatest widths of hind tibia and femur, respectively; calcipala small, slightly shorter than its width; pedisulcus well marked. Wing. Length $2.2 \mathrm{~mm}$; other characters as in female except subcosta sparsely or moderately haired. Abdomen. Basal scale brownish-black, with fringe of dark long hairs. Dorsal surface of abdomen medium brown to brownish-black except basal $1 / 2$ of segment 2 whitish-yellow, with dark short hairs; segments 2 , and 5-7 each with a pair of silvery iridescent spots dorsolaterally, those on segment 2 connected broadly to each other in the middle; ventral surface of abdomen pale except tergal plates medium to dark brown. Genitalia. Coxite in ventral view (Fig. 4C) nearly quadrate, and much shorter than style; style in lateral view (Fig. 4D) spatulate dorsoventrally; style in ventrolateral view (Fig. 2E) elongate, about 3.2 times as long as its greatest width at basal $1 / 3$, slightly sinuous, nearly parallelsided, with round apex having subterminal spine (though no spine on left style of 1 male); style in medial view (Fig. $4 \mathrm{~F}$ ) with long pointed protuberance basally on dorsal surface, bearing several small spinules on its anterior surface and at apex. Ventral plate in ventral view (Fig. 4C) with base nearly rectangular (thoughslightly rounded on each side), sparsely covered with setae medially; arms diverged forward and outward; ventral plate in lateral view (Fig. 4G) with distinct serrated posterior margin; ventral plate in end view (Fig. $4 \mathrm{H}$ ) with triangular base having both lateral margins strongly serrated, and with elliptical bare process protruding ventrally (though sparsely covered with setae on anterior surface). Median sclerite (Fig. 4I) plate-like, widening from base toward middle, then nearly parallelsided, well sclerotized and brown basally, but 


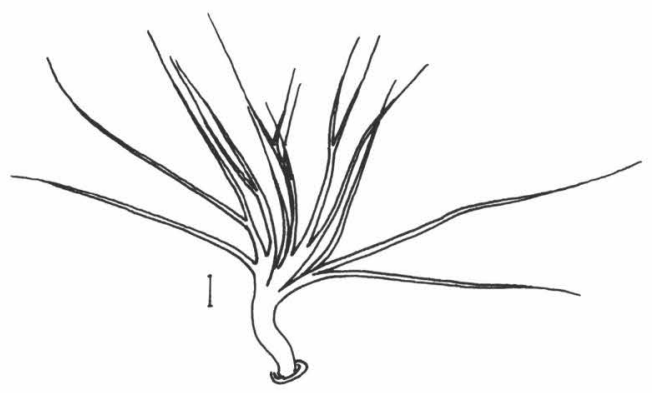

A

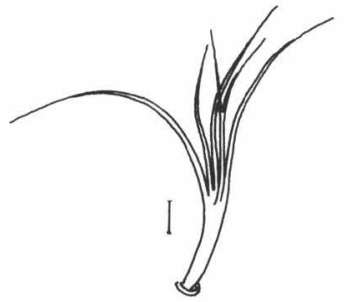

B

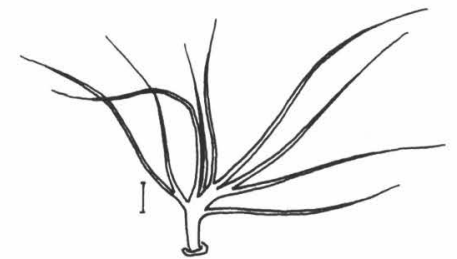

G

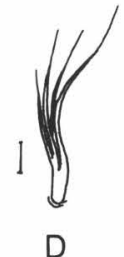

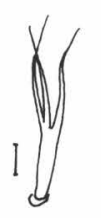

E

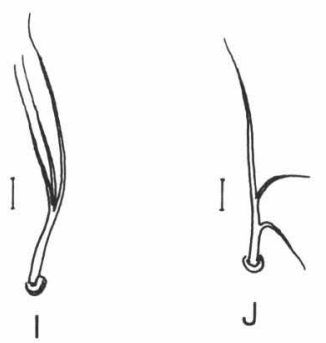

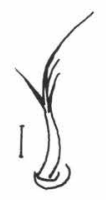

F

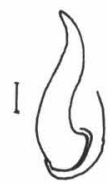

N

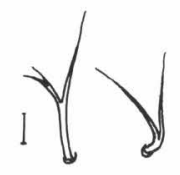

C

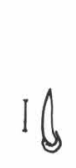

$\mathrm{K}$

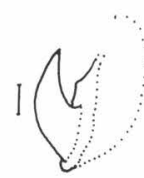

L
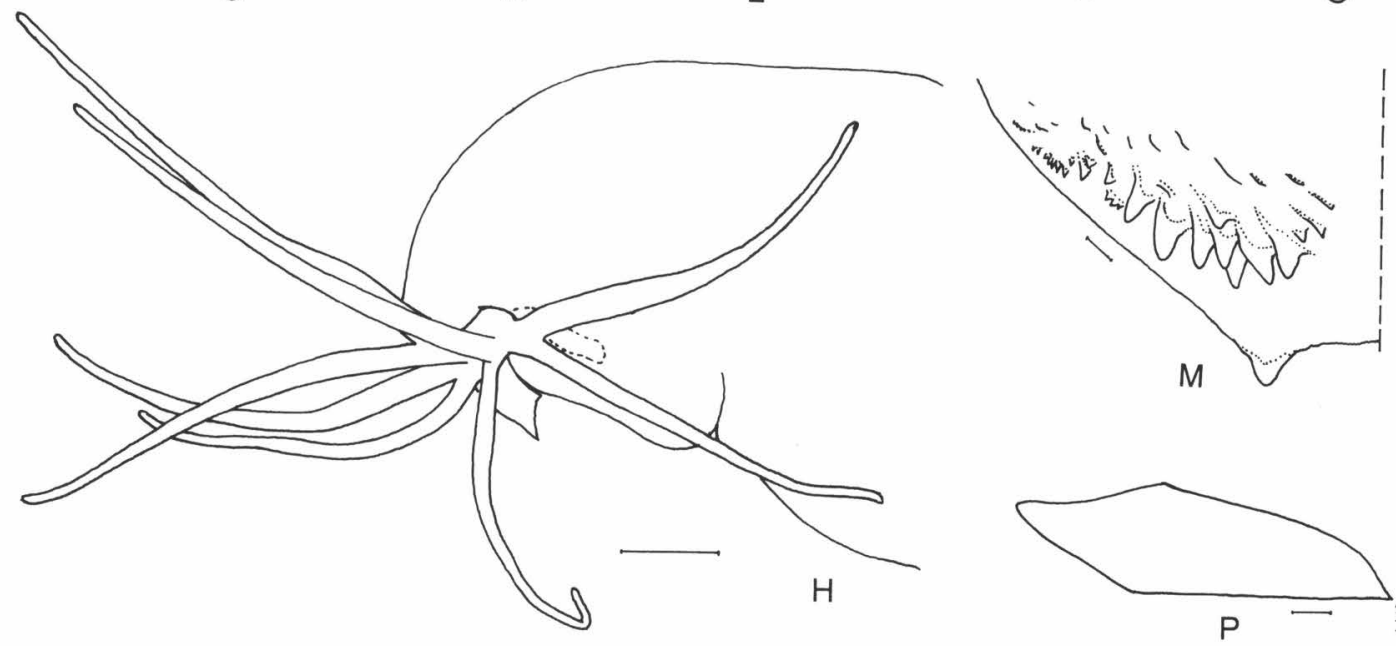

Fig. 5. Pupa of Simulium (Simulium) takense sp. nov. A and B, facial trichomes (A, usual trichome located anteriorly; B, additional trichome located ventromedially); C, frontal trichomes; D-G, trichomes on thorax (D, posterolateral; E-G, ventrolateral); H, gill filaments (left side, outer view); I, hair-like seta on dorsal surface of abdominal segment $1 ; \mathrm{J}$ and $\mathrm{K}$, hair-like seta and short spine on dorsal surface of abdominal segment 2, respectively; L, hook on dorsal surface of abdominal segment 3; M, spine-combs and terminal hook on dorsal surface of abdominal segment 9 (left half, dorsal view); N, hooklets on ventral surface of abdominal segment 4; $\mathrm{O}$, hook on ventral surface of abdominal segment 5 ; $\mathrm{P}$, cocoon (lateral view). Scale bars. $0.5 \mathrm{~mm}$ for $\mathrm{P} ; 0.2 \mathrm{~mm}$ for $\mathrm{H} ; 0.01 \mathrm{~mm}$ for $\mathrm{A}-\mathrm{G}$, and I-O. 
not so well sclerotized posteriorly, and then nearly transparent at least medially. Paramere (Fig. 2J) with several distinct hooks. Aedeagal membrane densely covered with minute setae, and with weakly sclerotized dorsal plate (Fig. 4 K). Abdominal segment 10 (Fig. 4L) without any distinct hair on ventral and lateral surfaces. Cercus (Fig. 4L) small, rounded, with 12 or 13 distinct hairs.

Pupa. Body length 3.0-3.2 mm. Head. Integument including antennal sheaths dark yellow to yellowish brown, densely covered with round tubercles; face with pair of long trichomes each with 13-17 branches (Fig. 5A) (in 1 male pupa, face with additional pair of long trichomes each with 6 branches ventrallyFig. 5B); frons with pair of bifid and/or trifid short trichomes (Fig. 5C). Thorax. Integument yellowish brown to medium brown, densely covered with small round and cone-shaped tubercles; thorax on each side with 3 long stout trichomes each with 16-19 branches (similar in size and shape to those on face, Fig. 5A) anterodorsally, 1 or 2 long stout trichomes each with ca. 16 branches (similar in size and shape to those on face, Fig. 5A) anterolaterally, 1 medium-long stout trichome with 2-4 branches (Fig. 5D) posterolaterally and 3 medium-long stout trichomes (1 with ca. 10 branches, 2 each with $2-4$ branches) (Fig. $5 \mathrm{E}-\mathrm{G}$ ) ventrolaterally. Gill (Fig. 5H) with 8 short filaments in 4 pairs widely divergent ( 2 pairs directed forward, 1 outward, 1 backward), all shortstalked except outwardly-directed pair almost sessile; all filaments short, somewhat varying in length $(0.8-1.3 \mathrm{~mm})$, and also in width (5 or 6 filaments somewhat inflated at least along basal $1 / 3$, width of thickest filament nearly twice that of thinnest one); all filaments unpigmented, tapered toward apex (except basal portions nearly parallel-sided or even slightly increased in width for certain lengths toward apex in some filaments), with distinct annular ridges and furrows forming indefinite reticulate surface patterns, and densely covered with minute tubercles. Abdomen. Dorsally, segment 1 weakly sclerotized, ocherous, sparsely covered with minute round tubercles, with 1 medium-long hair-like seta with 3-4 branches (Fig. 5I) on each side; segment 2 transparent, bare, with 1 medium-long hair-like seta with 3 or 4 branches (Fig. 5J) and 5 short stout spines (Fig. $5 \mathrm{~K}$ ) on each side; segments 3 and 4 transparent, each with 4 distinct simple hooks (Fig. 5L) and
1 short stout spine on each side; segments $5^{-7}$ transparent, lacking spine-combs; segments 69 each with comb-like groups of minute spines on each side; segment 8 transparent (though weakly sclerotized and yellow at and near base of spine-combs), with distinct spine-combs in transverse row; segment 9 weakly sclerotized and yellow, with distinct spine-combs in transverse row (Fig. 5M) on each side, and pair of cone-shaped terminal hooks (Fig. 5M). Ventrally, segments 3-8 nearly transparent and segment 9 weakly sclerotized and yellow; segments 3-8 with comb-like groups of minute spines; segment 4 with 2 stout hooklets each with $2-4$ apical branches (Fig. $5 \mathrm{~N}$ ) submedially and a few slender minute setae on each side; segment 5 with pair of simple stout hooks (Fig. 50) submedially and a few simple short setae on each side; segments 6 and 7 each with pair of simple stout hooks (similar in size and shape to those on segment 5-Fig. 50) (1 inner hook on segment 7 in 1 male pupa bifid apically) somewhat separated from each other, and a few simple short setae on each side. Grapnelshaped hooklets absent on each side of segment 9. Cocoon (Fig. 5P). Shoe-shaped, with high anterior collar, tightly woven, with or without open spaces in webs of anterior collar, not extending ventrolaterally; individual threads visible or invisible; $4.3-5.0 \mathrm{~mm}$ long by $1.8-2.0 \mathrm{~mm}$ wide.

Mature larva. Unknown.

TYPE SPECIMENS. Holotype female with its associated pupal exuvia and cocoon, same data and date as the holotype of S. (G.) prayongi sp. nov. Paratype: 2 females, 2 males, each with its associated pupal exuvia and cocoon, same data and date as those of the holotype.

ECOLOGICAL NOTES. The pupae of S. (S.) takense sp. nov. were collected from the surface of rocks in the water of the same stream as noted for $S$. (G.) prayongi sp. nov. Most of the pupae and their cocoons of this species, as well as stones in the streambed and submerged trailing grasses, were covered with a thick layer of calcareous sediments.

Associated species was $S$. (G.) prayongi sp. nov. 
ETYMOLOGY. The specific name takense refers to the name of the province, Tak, where this new species was collected.

REMARKS. According to the keys (Takaoka, 2003), S. (S.) takense sp. nov. is assigned to the multistriatum speciesgroup of the subgenus Simulium s. str. by having the scutum with five longitudinal vittae, simple claws in the female, the style with long basal protuberance (Fig. $2 \mathrm{~F}$ ), the ventral plate with toothed posterior margin (Fig. 2G, H) in the male, and the gill with eight filaments (Fig. $3 \mathrm{H}$ ) in the pupa.

This new species appears to be closely related to $S$. (S.) chaliowae Takaoka and Boonkemtong, S. (S.) chinarongi Kuvangkadilok and Takaoka, S. (S.) triglobus Takaoka and Kuvangkadilok, all described from Thailand (Takaoka and Kuvangkadilok, 1999) in having the shoe-shaped cocoon (Fig. 5P), a character rarely occurring in the multistriatum species-group, of which most species have a wall-pocketshaped cocoon with anterolateral windows.

This new species is easily distinguished from all these three known species in the female by the paraproct only slightly protruding ventrally beyond the level of the cercus (Fig. $3 \mathrm{H}$ ) and ovipositor valves with several stout hairs (Fig. $3 \mathrm{E}$ ), and in the pupa by the gill filaments widely divergent (Fig. $5 \mathrm{H}$ ) and the presence of distinct spine-combs and terminal hooks on the abdominal segment 9 (Fig. 5M). The male of this new species is easily distinguished from that of $S$. (S.) chaliowae by the bicolored hind basitarsus (Fig. 4B) (cf., entirely darkened in $S$. (S.) chaliowae), and from that of $S$. (S.) chainarongi by the ventral plate with concave posterior margin (Fig. 4C) (cf., ventral plate with convex posterior margin in $S$. (S.) chainarongi).

\section{ACKNOWLEDGEMENT}

This work was financially supported by a Grant-in-Aid of Japan-US Medical Research Cooperation Program (the fiscal year 2004).

\section{REFERENCES}

Takaoka, H. 2000. Taxonomic notes on Simulium (Gomphostilbia) gombakense (Diptera: Simuliidae) from Peninsular Malaysia: Descriptions of male and pupa, and subgeneric transfer from Morops to Gomphostilbia. Jpn. J. Trop. Med. Hyg., 28: 111-114. Takaoka, H. 2003. The Black Flies (Diptera: Simuliidae) of Sulawesi, Maluku and Irian Jaya. xxii +581 pp., Kyushu University Press, Fukuoka.

Takaoka, H. and Davies, D. M. 1995. The Black Flies (Diptera: Simuliidae) of West Malaysia. viii +175 pp., Kyushu University Press, Fukuoka.

Takaoka, H. and Kuvangkadilok, C. 1999. Four new species of black flies (Diptera: Simuliidae) from Thailand. Jpn. J. Trop. Med. Hyg., 27: 497-509.

Takaoka, H. and Sigit, S. H. 1997. Three new blackfly species of Simulium (Diptera: Simuliidae) from Sumatra, Indonesia. Jpn. J. Trop. Med. Hyg., 25: 69-80. 